\title{
Behavioral Sensitization to Kainic Acid and Quisqualic Acid in Mice: Comparison to NMDA and Substance P Responses
}

\author{
Xiaofeng Sun and Alice A. Larson \\ Department of Veterinary Biology, University of Minnesota, St. Paul, Minnesota 55108
}

\begin{abstract}
Substance $P$ (SP) and the excitatory amino acid (EAA) agonists NMDA, kainic acid (KA), or quisqualic acid (Quis) each produce a transient, caudally directed biting and scratching response (CBS) in mice after their intrathecal injection. We have previously shown that repeated injections of SP result in a decrease in the intensity of CBS, or desensitization. The goals of the present study were (1) to determine whether desensitization also develops to the CBS behavior produced by EAAs in the spinal cord, (2) to characterize the role of interneurons in desensitization, and (3) to examine possible interactions between EAAs and SP. While injection of NMDA at 2 min intervals resulted in desensitization to its CBS behavioral effect, behavioral responses to repeated injections of KA or Quis increased in intensity, exhibiting sensitization. The NMDA antagonist DL-2-amino-5-phosphonovaleric acid failed to alter sensitization to either KA or Quis but inhibited behaviors produced by SP and NMDA, suggesting an NMDAmediated component in SP-induced behavior. Concanavalin $A$, which is reported to block desensitization to the electrophysiologic effect of Quis, blocked sensitization to the behavioral effects of both Quis and KA. Strychnine, bicuculline, and 5-aminovaleric acid each inhibited desensitization to SP and NMDA, supporting the notion of recruitment of inhibitory transmitters in the attenuation of NMDA and SP activity. Pretreatment with capsaicin selectively inhibited the development of behavioral sensitization to KA, suggesting an involvement of small-diameter $C$-fibers in the enhancement of responsivity to KA. Consistent with this, pretreatment with SP selectively potentiated the CBS response to KA. The potentiation of KA effects by SP and dependence of KA behavioral sensitization on $C$-fiber activity suggest a possible mechanism by which EAAs and SP may be involved in the mediation of pain.
\end{abstract}

The undecapeptide substance $\mathrm{P}(\mathrm{SP})$ and the acidic amino acids, Glu and Asp are found in high concentrations in the dorsal horn of the spinal cord (Besson and Chaouch, 1987), where they are believed to act as excitatory neurotransmitters (Schneider and Perl, 1988). There are currently three major excitatory amino

\footnotetext{
Received Dec. 11, 1990; revised Mar. 1, 1991; accepted May 29, 1991.

This research was supported by U.S. Public Health Service Grants DA04090, DA04190, and DA00124. We gratefully acknowledge the excellent editorial assistance of Drs. David H. Smullin, Stephen R. Skilling, Christopher W. Murray, and David R. Brown.

Correspondence should be addressed to Dr. Alice A. Larson, Department of Veterinary Biology, University of Minnesota, 295 Animal Science/Veterinary Medicine Building, 1988 Fitch Avenue, St. Paul, MN 55108.

Copyright (C) 1991 Society for Neuroscience $0270-6474 / 91 / 113111-13 \$ 05.00 / 0$
}

acid (EAA) receptor subtypes that have been classified based on the preferential activation of these receptors by the EAA agonists NMDA, kainate (KA), and quisqualate (Quis) (Evans et al., 1978, 1979; McLennan and Lodge, 1979; Foster and Fagg, 1984).

In the spinal cord, SP is thought to act as a primary afferent transmitter that is especially important in nociceptive transmission (Lembeck, 1953; Salt and Hill, 1983; Besson and Chaouch, 1987). Intrathecal administration of SP to mice elicits a dose-dependent, caudally directed biting and scratching (CBS) behavior (Hylden and Wilcox, 1981; Piercey et al., 1981) that has been postulated to reflect aversive activity (Sakurada et al., 1988; Wilcox, 1988). This behavioral model has been widely used as a tool to investigate the pharmacological effects of excitatory compounds in the CNS, especially with respect to pain transmission. Using this paradigm, we have demonstrated that repeated intrathecal injections of SP result in a decreased intensity of CBS behavior with each subsequent injection, that is, desensitization (Larson, 1988). Behavioral desensitization is a decrease in the response to an agonist and can be brought about by a variety of mechanisms. SP, for example, typically exhibits a rapid desensitization in several systems (Laufer et al., 1988) and is thought to result from decreased activity at neurokinin-1 receptors. The ability of SP to induce hyperalgesia in rats has also been found to exhibit desensitization (Moochhala and Sawynok, 1984). Desensitization to the CBS behavioral effects of SP appears to result from the action of inhibitory metabolites that attenuate the response to SP rather than downrcgulation of neurokinin-1 receptors (Larson, 1988; Igwe et al., 1990a,b,c).

Intrathecal administration of EAAs also elicits CBS behaviors (Aanonsen and Wilcox, 1986, 1987). This is of special interest as Glu and Asp have been postulated to be involved in pain transmission, based on several lines of evidence: (1) Glu is colocalized with SP in primary afferent C-fibers (De Biasi and Rustioni, 1988); (2) injection of formalin into the hindpaw of rats evokes the release of Glu and Asp in the dorsal spinal cord (Skilling et al., 1988); (3) antagonists of EAAs inhibit nociception (Cahusac et al., 1984; Aanonsen and Wilcox, 1987); and (4) intrathecal injections of NMDA produce an apparent hyperalgesic effect (Aanonsen and Wilcox, 1987). SP and EAAs also appear to interact in a reciprocal fashion in the spinal cord as SP causes the release of Glu and Asp from the dorsal horn of rats (Smullin et al., 1990) and KA in turn elicits the release of SP in the same system (Murray et al., 1990). While the acute effects of EAAs and SP in the spinal cord have been extensively studied, their effects and interactions after tonic release or application have not been studied in the whole animal.

Electrophysiologically, responses to EAAs in invertebrates have been found to exhibit a profound use-dependent decrement in responsivity (Takeuchi and Takeuchi, 1964). While it was 
initially thought that vertebrate neurons failed to develop desensitization (O'Brien and Fischbach, 1986), the use of improved drug delivery systems showed that these EAA receptors do exhibit rapid desensitization. The decrease in NMDA receptor responsivity appears to be calcium dependent and requires several seconds (Mayer and Westbrook, 1985; Zorumski et al., 1989). In contrast, desensitization to Quis and $R S-\alpha-$ amino-3-hydroxy-5-methyl-4-isoxazole-propionic acid $\mathrm{HBr}$ (AMPA), an agonist at the same receptor as Quis, occurs within milliseconds and recovers within hundreds of milliseconds (Trussell et al., 1988; Tang et al., 1989). The response to KA exhibits little or no desensitization (Mayer et al., 1989). While these studies demonstrate desensitization to specific EAA agonists, it is unclear what the consequences of this desensitization are in the intact animal with respect to specific physiologic effects. In light of the tendency of EAAs to desensitize, it is important to determine whether the tonic release of EAAs or SP, such as would occur during chronic pain, might influence the intensity of the response to a subsequent release of one of these neurotransmitters and thereby influence the perception of pain.

If EAAs play a role in the mediation of pain, and if changes in the sensitivity to EAAs occur in these pathways, these changes would provide natural regulatory (analgesic or hyperalgesic) effects. The purpose of the present investigation was to study the effect of prolonged exposure of the spinal cord to the EAA agonists NMDA, KA, and Quis to determine whether the behavioral effects produced by these compounds, like those of SP, are altered after repeated injections. We used the paradigm of monitoring EAA- and SP-induced CBS behaviors to detect changes in the sensitivity of the spinal cord to these compounds because of the ease in quantifying CBS behaviors in unanesthetized, intact mice. We then examined the effect of tonic exposure to one compound on the response to the other excitatory compounds to detect changes in their interaction in the spinal cord in vivo. The potential role of interneurons in the mediation of behavioral sensitization or desensitization was then examined using antagonists of NMDA, GABA, and glycine.

\section{Materials and Methods}

Animals. Male Swiss-Webster mice (20-25 gm, Biolab, White Bear Lake, MN) were housed four per cage and allowed to acclimate for at least $24 \mathrm{hr}$ prior to use in experiments. Mice were allowed free access to food and water. Animals were used strictly in accordance with the Guidelines of the University of Minnesota Animal Care and Use Committee and those prepared by the Committee on Care and Use of Laboratory Animals of the Institute of Laboratory Animal Resources, National Research Council [DHEW Publication (NIH) 78-23, revised 1978].

Drug administration. All injections were made intrathecally in mice at approximately the L5-L6 intervertebral space using a 30-gauge 0.5 inch disposable needle and a 50- $\mu$ Luer tip Hamilton syringe after the method of Hylden and Wilcox (1980). A cannula constructed of a 30gauge needle attached to PE-10 tubing was used for repeated intrathecal injections as described elsewhere (I arson and Beitz, 1988). A volume of $5 \mu \mathrm{l}$ was used for all intrathecal injections. SP was administered in $0.85 \%$ acidified saline, containing $0.01 \mathrm{~N}$ acetic acid (Hall and Stewart, 1986). For repeated injections of SP, $10 \mathrm{ng}(7.5 \mathrm{pmol})$ wcre delivered four times at $2 \mathrm{~min}$ intervals. For repeated injection of EAA agonists, $0.2 \mathrm{nmol}$ of NMDA, $0.025 \mathrm{nmol}$ of $\mathrm{KA}$, and $0.3 \mathrm{nmol}$ of Quis were administered in $0.85 \%$ normal saline at 2 -min intervals. The doses of $\mathrm{SP}$ and EAA agonists were chosen to be equieffective based on their ability to elicit CBS behaviors that were of similar intensity and of sufficient magnitude to be either significantly inhibited or potentiated.

Experimental protocol. Immediately after insertion of the cannula, animals were placed in a large glass cylinder containing approximately $2 \mathrm{~cm}$ of bedding. One minute later, mice were injected via the cannula, and the total number of bites and scratches occurring over the subse-

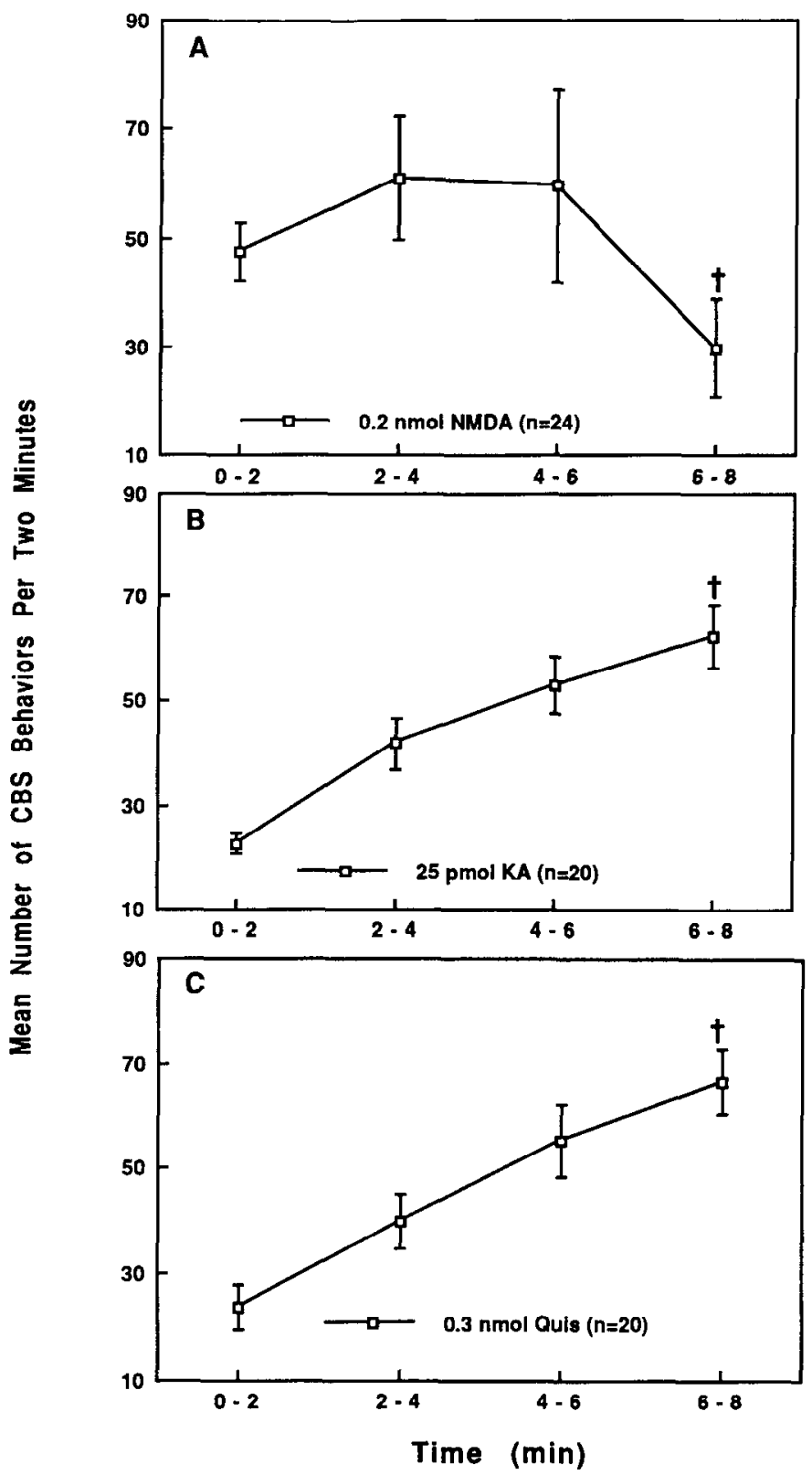

Figure 1. Caudally directed biting and scratching responses to repeated intrathecal injections of EAAs in mice. $A$, Desensitization to the effect of repeated injections of $0.2 \mathrm{nmol}$ of NMDA. $B$, Sensitization to the effect of $25 \mathrm{pmol}$ of KA. $C$. Sensitization to the effect of $0.3 \mathrm{nmol}$ of Quis. Agents were injected at $0,2,4$, and $6 \mathrm{~min}$. Bchavioral responses were monitored for the 2-min period following each injection. Daggers indicate a statistically significant difference $(p<0.05)$ between the mean responses to the first and fourth injections using Student's $t$ test. Points indicate the mean $( \pm S E)$ number of CBS responses obtained from either NMDA, where $n=24$, or from KA or Quis, where $n=20$.

quent $2 \mathrm{~min}$ interval was recorded. Mice were reinjected evcry $2 \mathrm{~min}$, and the behaviors were recorded for a series of four injections. Injection of saline or acidified saline in the same volume and time interval failed to elicit biting and scratching behavior and appeared to have no effect on the normal exploratory behavior of the mice.

Drugs. Substance P (SP) was purchased from Peninsula Laboratories (Belmont, CA). $N$-methyl-D-aspartic acid, kainic acid, quisqualic acid, DL-2-amino-5-phosphonovaleric acid (APV), bicuculline, 5-aminovaleric acid hydrochloride (5-AVA), capsaicin, and strychnine were purchased from Sigma Chemical Company (St. Louis, MO). Concanavalin A (Con A) from jack bean Canavalia ensiformis, specific for $\alpha$-D-man- 

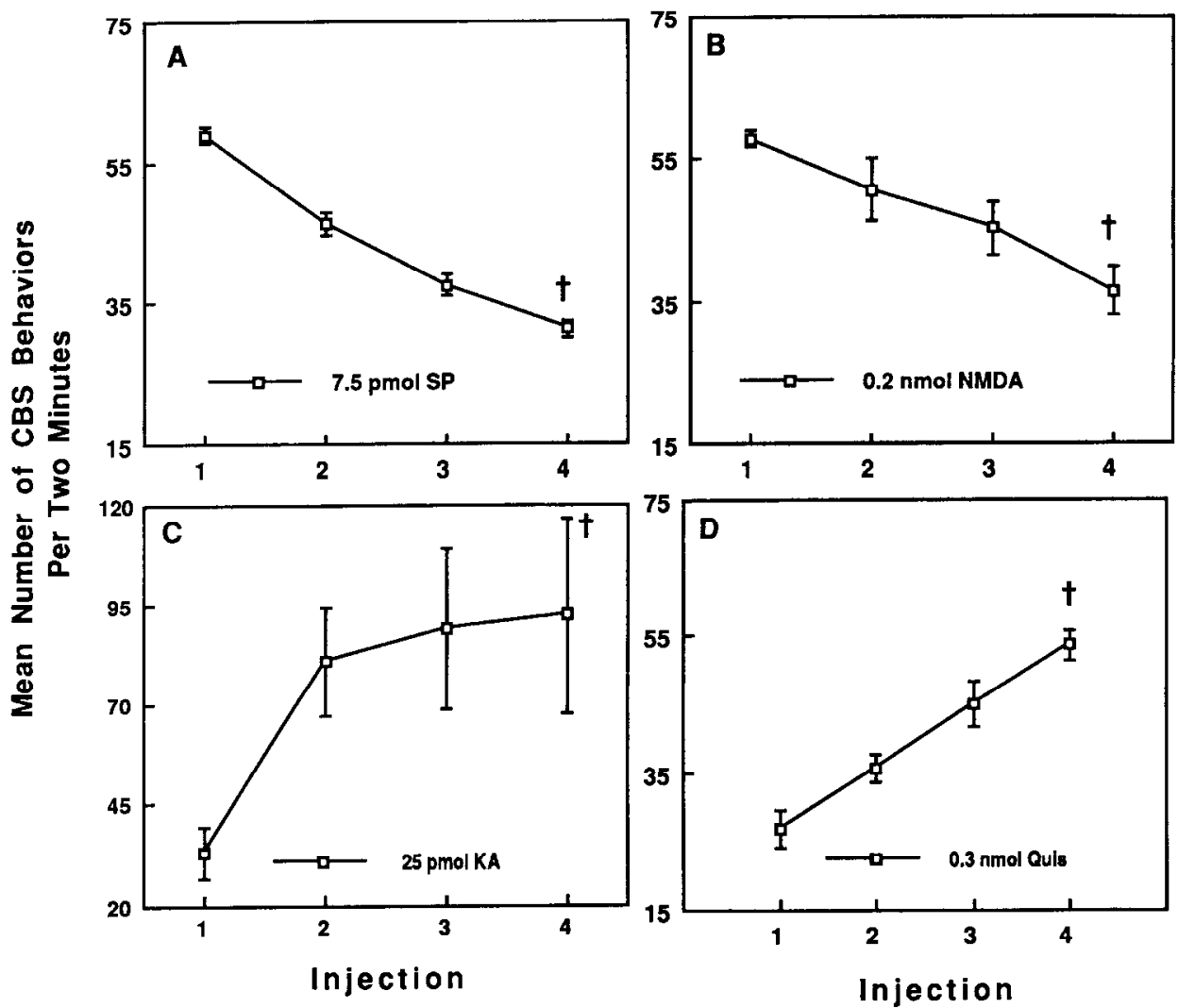

Figure 2. Desensitization to the effects of repeated injections of $7.5 \mathrm{pmol}$ of SP $(A)$ or $0.2 \mathrm{nmol}$ of NMDA $(B)$, characterized by decreases in the intensity of their behavioral responses, is compared to sensitization to the effect of repeated injections of $25 \mathrm{pmol}$ of KA (C) or $0.3 \mathrm{nmol}$ of Quis $(D)$, characterized by significant increases in the intensity of their behavioral responses. Rather than injection of mice at $2 \mathrm{~min}$ intervals, mice were not injected with the second, third, and fourth doses of each compound until the end of each behavioral episode, as judged by a 10 sec interval during which the mouse exhibited no CBS behavior. Each point represents the mean $( \pm \mathrm{SE})$ number of CBS responses exhibited by a group of six mice. Daggers indicatc a statistically significant difference $(p<0.05)$ between the mean responses to the first and fourth injections using Student's $t$ test. nose $>\alpha$-D-glucose $>\alpha-D-G l c N A c$, was purchased from Boehringer Mannheim (Indianapolis, IN).

Statistics. Statistical analysis of the results was performed using Student's $t$ test for unpaired or paired samples with significance accepted at $p<0.05$. The results of cross-desensitization and cross-sensitization are expressed graphically as the percentage of a control group, as indicated in Results, but evaluated statistically prior to data transformation.

\section{Results}

Sensitization and desensitization. Responses to repeated intrathecal injections of $0.2 \mathrm{nmol}$ of NMDA resulted in an inverted U-shaped curve over time, as shown in Figure $1 A$. The number of behaviors after the fourth injection of NMDA was significantly less than those resulting from the first injection of NMDA, suggesting desensitization. Injection of half that dose of NMDA $(0.1 \mathrm{nmol})$ failed to produce a significantly different response in any of the four responses.

In contrast to NMDA, repeated intrathecal injections of either KA or Quis resulted in the development of a dramatic and readily reproducible sensitization to the behavioral effects of these EAAs (Fig. 1B,C). The intensity of responses typically increased two to three times the response to the first injection. To determine whether the increased behavioral response to either KA or Quis was the result of a simple accumulation of drug in the spinal area, KA or Quis was administered repeatedly at the same dose as used in Figure $1, B$ and $C$, but was not reinjected until the behavioral response to each injection had terminated. The criterion used to determine that the effect of each injection had terminated was the observation of a $10 \mathrm{sec}$ period during which there were no CBS behaviors. As shown in Figure 2, the intensity of each behavioral episode increased with each injection. In spite of the increase in the time interval between injec- tions caused by the delay between behavioral episodes, the intensity of the response to each injection of KA or Quis still increased, again suggesting the development of sensitization to KA- and Quis-induced CBS behavior rather than a simple accumulation of drug in the spinal area. Four repeated injections of KA administered at 15-min intervals still significantly increased the behavioral response of the last injection by $53 \%$ over that obtained in response to the first injection (data not shown).

It is possible that behavioral sensitization or desensitization to these excitatory compounds results from an action in the supraspinal area. To determine the likelihood of this, we examined the distribution of dye injected intrathecally. No dye was detected in the supraspinal area of mice 2 min after the last of four $2 \mu \mathrm{l}$ volumes injected intrathecally at $2 \mathrm{~min}$ intervals. In contrast, $8 \mathrm{~min}$ after a bolus injection of $8 \mu$ of dye, there was substantial staining of the brainstem area. When drugs were injected in four $2 \mu \mathrm{l}$ volumes at $2 \mathrm{~min}$ intervals, which appeared to result in little or no distribution to the supraspinal area, behavioral sensitization to KA and Quis and desensitization to SP and NMDA were still produced, suggesting that the major anatomical site involved in the development of behavioral sensitization and desensitization is the spinal cord.

Recovery from desensitization and sensitization. The recovery of the behavioral response from the desensitizing effect of repeated injections of NMDA was observed by $7 \mathrm{~min}$ after the last of a series of four injections of $0.2 \mathrm{nmol}$ NMDA (Fig. $3 A$ ). Recovery of the desensitization to SP-induced CBS behavior has also been shown to occur within 5-10 min (Larson, 1988). Complete recovery from the sensitization to $\mathrm{KA}$ and Quis occurred by $7 \mathrm{~min}$ after the fourth injection of $25 \mathrm{pmol}$ of $\mathrm{KA}$ and $17 \mathrm{~min}$ after the fourth injection of $0.3 \mathrm{nmol}$ of Quis, as 

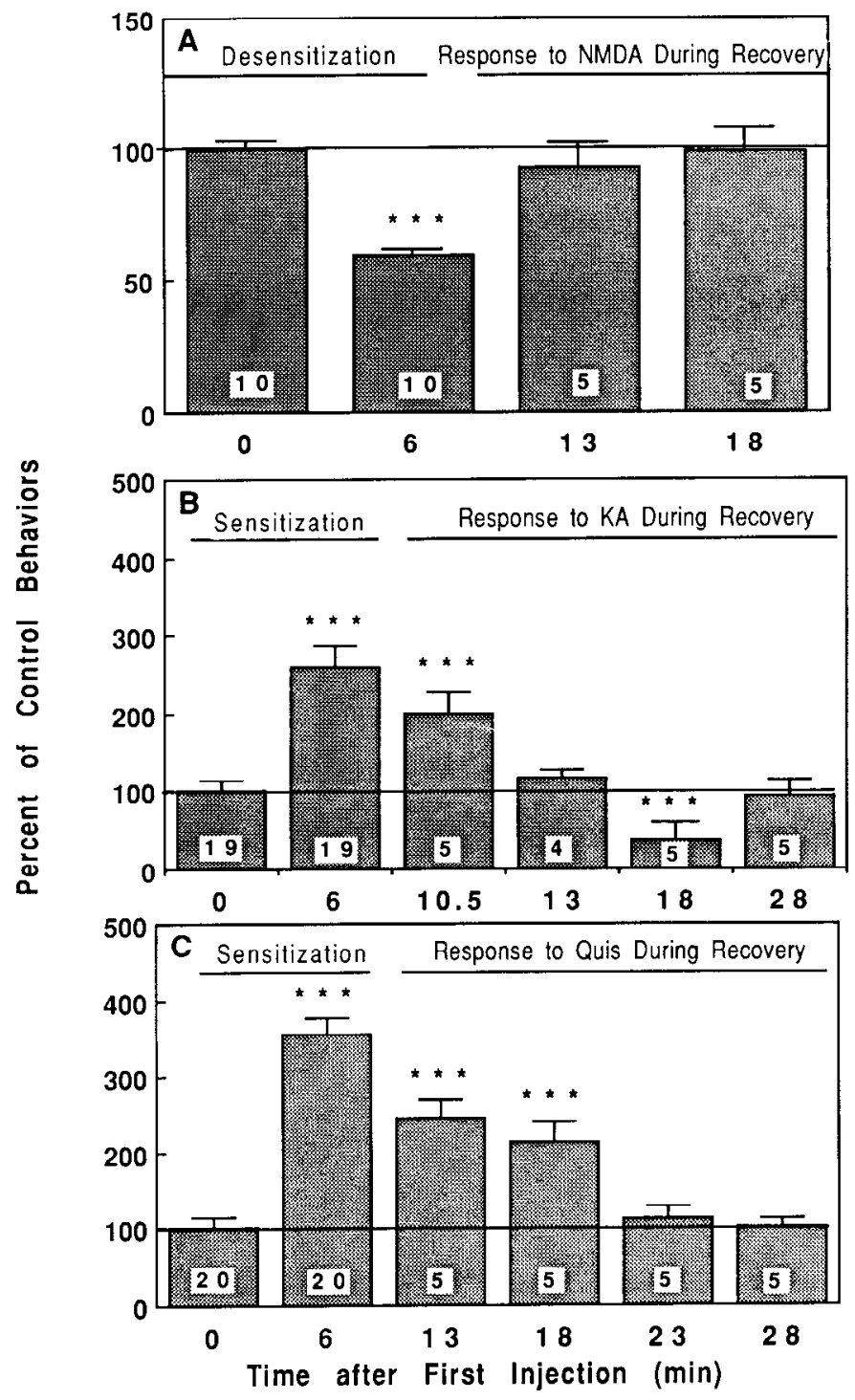

Figure 3. Recovery from the sensitizing and desensitizing effect of EAA agonist-induced CBS behaviors. The first two bars represent the mean number $( \pm S E)$ of responses, as a percentage of the response to the first injection, over a 2 min interval after the first and fourth injections. The last two bars in $A$ and the last three bars in $B$ and $C$ represent the mean intensity of the response to a final intrathecal injection at the time indicated. Numbers in the bars represent the total number of animals tested in each group. Statistical significance was assessed prior to transformation of data. Asterisks indicate a significant difference in the number of CBS behaviors when challenged at each time indicated compared to the first injection, where $* * *$ indicates $p<0.001$ between the test and control groups. Control values were not found to differ significantly from each other and therefore are averaged for simplification of their graphical presentation. $A$, Complete recovery of NMDA-induced CBS behavior was observed by $18 \mathrm{~min}$ after the first injection of the NMDA. $B$, Complete recovery of the KA-induced CBS behavior was seen by $28 \mathrm{~min}$ after the first injection. $C$, Complete recovery of Quisinduced CBS behavior was seen by $28 \mathrm{~min}$ after the first injection.

indicated by a behavioral response to a challenge injection that was equivalent to that in mice previously injected with saline only (Fig. 3B,C). Recovery from the sensitizing effect of Quis was longer and was not accompanied by a transient decreased responsivity. It appears that neither the decreased response to repeated injections of NMDA nor the increased response to either KA or Quis resulted from spinal damage caused by the intrathecal injection per se as injections of vehicle prior to injection of the EAA did not alter the response to the EAA.

Effect of $A P V$. Pretreatment at $1 \mathrm{~min}$ with $1 \mathrm{nmol}$ of APV, an NMDA antagonist, followed by coadministration of NMDA with $0.12 \mathrm{nmol}$ of APV, significantly inhibited the intensity of NMDA-induced CBS behaviors produced by each of four repeated injections of NMDA (Fig. 4B). APV had no effect on the intensity of CBS elicited by a similar series of four injections of KA or Quis (Fig. $4 C, D$ ). While APV appears to be selective for NMDA, identical injections of APV with SP also markedly inhibited the CBS behavior produced by a series of three injections of SP (Fig. $4 A$ ). The effect of APV on the fourth injection of SP is not shown as several of these mice exhibited seizures at that time in response to this treatment paradigm and were immediately killed. The effect of APV on the responses to both NMDA and SP appcars to be a simple inhibition of the effect of these compounds rather than an effect on the development of desensitization as the response to the first injection is inhibited by APV to a similar degree as the behavioral response to the third and fourth injections. The inhibition of SP behavior by APV appears to require pretreatment with APV, as coadmininistration of SP plus $1 \mathrm{nmol}$ of APV failed to alter the response to a single injection of SP, as previously described by Aanonsen and Wilcox (1986).

Effect of con $A$. When tested electrophysiologically, repeated exposure to Quis results in a dramatic desensitization that is prevented by the lectin Con A (Mayer and Vyklicky, 1989). To determine the relationship between the behavioral sensitization observed in the present studies and the previously reported desensitization to Quis, we examined the effect of Con A on the behavioral response to repeated injections of EAAs and SP. A dose of 300 pmol of Con $\Lambda$ was injected intrathecally $1 \mathrm{~min}$ prior to the series of four injections of either SP, NMDA, KA, or Quis. At this dose, Con A completely blocked the development of sensitization to KA and Quis in addition to an inhibitory effect on the magnitude of the first response to Quis (Fig. 5C,D). The same dose of Con A had no effect on any of the four injections of NMDA and a small inhibitory effect on the magnitude of all reponses to SP (Fig. $5 A, B$ ).

Effect of $G A B A_{A}$ antagonism. Pretreatment with $10 \mathrm{pmol}$ of the $\mathrm{GABA}_{\mathrm{A}}$ antagonist bicuculline, $1 \mathrm{~min}$ prior to injection of EAAs or SP, did not alter the intensity of CBS behavior produced by a single injection of SP or any of the EAAs. Bicuculline did, however, protect against the development of desensitization to the behavioral effects of both NMDA and SP, as shown in Figure $6, A$ and $B$. In contrast, pretreatment with bicuculline failed to alter the development of sensitization to either KA or Quis (Fig. 6C,D). Intrathecal injection of this relatively low dose of bicuculline alone failed to elicit CBS behaviors over the 9 min test period.

Effect of $G A B A_{B}$ antagonism. Pretreatment with $2 \mathrm{nmol}$ of 5-AVA, a $\mathrm{GABA}_{\mathrm{B}}$ antagonist, $5 \mathrm{~min}$ prior to challenge with EAAs and SP did not alter the intensity of behavioral responses to a single injection of SP, NMDA, KA, or Quis (Fig. 7). Similar to the response profile elicited by pretreatment with bicuculline, 5-AVA pretreatment selectively inhibited the development of desensitization to SP and NMDA (Fig. $7 A, B$ ) without affecting the development of sensitization to either KA or Quis (Fig. $7 C, D$ ). No CBS behaviors were observed during the $13 \mathrm{~min}$ observation period following injection of $2 \mathrm{nmol}$ of 5-AVA alone. 

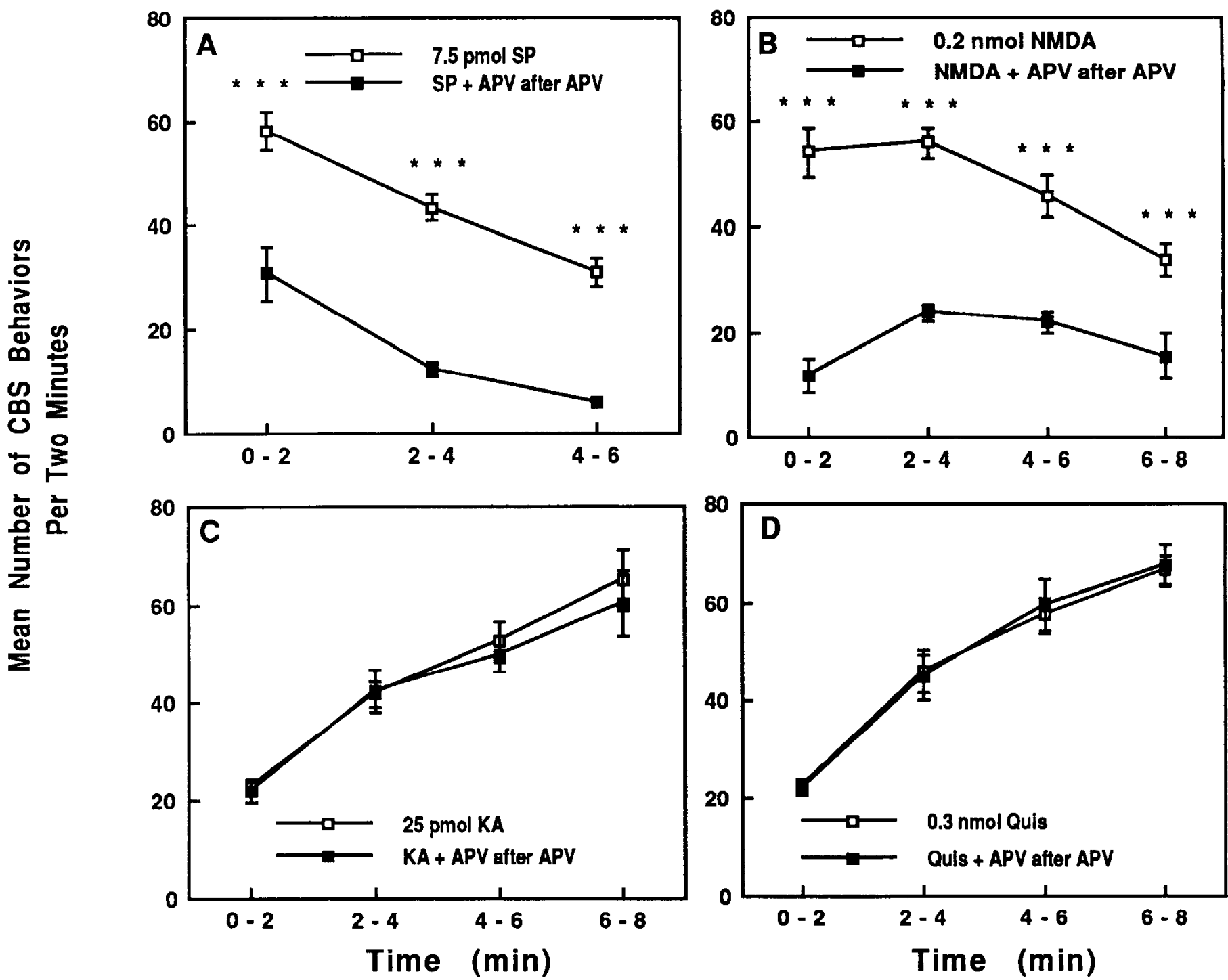

Figure 4. Inhibition of effects of SP and NMDA, but not KA or Quis, by APV. A dose of $1 \mathrm{nmol}$ of APV was administered 1 min before repeated injections of either $7.5 \mathrm{nmol}$ of SP, $0.2 \mathrm{nmol}$ of NMDA, $25 \mathrm{pmol}$ of KA, or $0.3 \mathrm{nmol}$ of Quis. In addition to the pretreatment with APV, 0.12 $\mathrm{nmol}$ of APV was coadministered with each excitatory compound at 2 min intervals. Solid squares represent mean number ( \pm SE) of CBS behaviors in the presence of APV. Open squares represent mean number $( \pm \mathrm{SE})$ of CBS behaviors induced by SP or EAAs alone. Asterisks indicate significant differences between the APV-treated and control groups: ***, $p<0.001 ; n=5$ micc per group. $A$, APV significantly inhibitcd SP-induced CBS behavior. The fourth injection of SP plus APV is deleted as seizures typically resulted from this final injection. $B$, APV inhibited the intensity of NMDA-induced CBS behavior. $C, \mathrm{KA}$-induced responses and the development of sensitization to KA were not altered by APV. $D$, APV failed to alter Quis-induced behaviors or sensitization to Quis.

Effect of glycine antagonism. Pretreatment with $0.3 \mathrm{nmol}$ of strychnine $1 \mathrm{~min}$ prior to coadministration of an additional 75 pmol of strychnine with NMDA was found to be sufficient to reverse the inhibitory effects of glycine on NMDA. While strychnine had no effect on the initial response to either SP or NMDA, the addition of strychnine to the injection protocol inhibited the development of desensitization to both NMDA as well as SP (Fig. 8A,B). The addition of strychnine with $\mathrm{KA}$ or Quis had no effect on the development of sensitization to their behavioral responses (Fig. $8 C, D$ ). The CBS behaviors resulting after the injection of strychnine alone were not significantly greater than the random grooming behaviors seen after injection of saline.

Effect of pretreatment with capsaicin. Pretreatment with 0.8 $\mu \mathrm{g}$ of capsaicin $24 \mathrm{hr}$ prior to the the injection of SP or EAAs was found to inhibit dramatically the development of sensiti- zation to repeated injections of KA compared to the response observed in vehicle-injected control mice pretreated with $5 \mu \mathrm{l}$ of a mixture $(\mathrm{v} / \mathrm{v})$ of $50 \%$ saline and $50 \%$ dimethylsulfoxide (DMSO) (Fig. 9C). Pretreatment of mice with capsaicin failed to alter the magnitude of behavioral responses to either SP or Quis (Fig. 9A,D). While the response to a single injection of NMDA was not altered, behavioral desensitization to NMDA was slightly inhibited by pretreatment with capsaicin (Fig. 9B). The dose of capsaicin was chosen based on its ability to produce analgesia in the hot plate and abdominal stretch assays (Larson, 1989).

Cross-desensitization. To determine whether desensitization to either NMDA or SP resulted in cross-desensitization with other excitatory compounds, mice were pretreated with three injections of either NMDA, SP, or vehicle and then challenged 

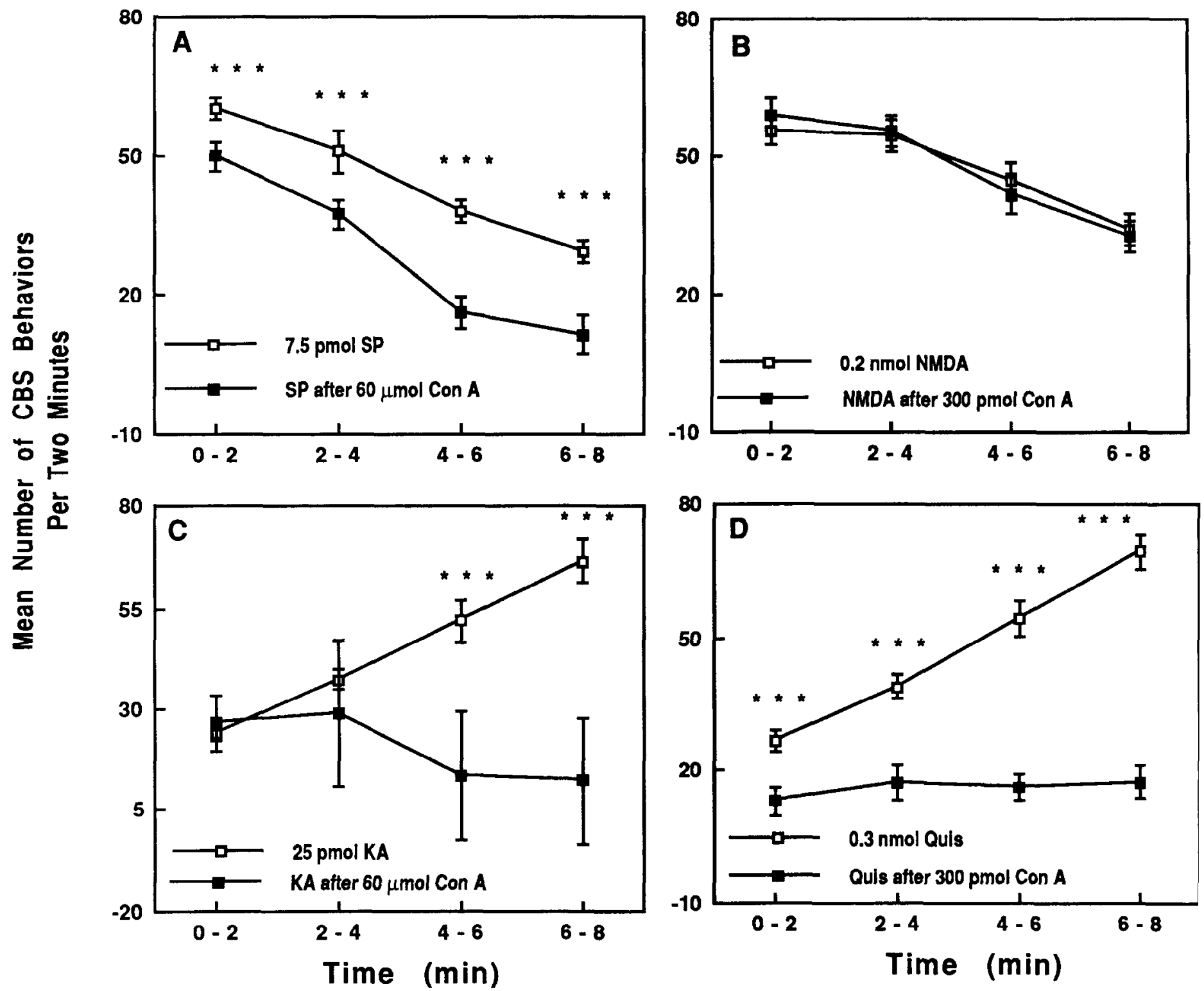

Figure 5. Protection against the development of sensitization to the CBS behavioral effects of KA and Quis by Con A. Groups of five mice were pretreated intrathecally with either saline or $300 \mathrm{pmol}$ of Con A 1 min prior to repeated injection of excitatory compounds. Each point represcnts the mean number $( \pm S E)$ of CBS behaviors produced during a 2 min interval after each compound. Asterisks represent significant differences between the Con A and control groups: ${ }^{* * *}, p<0.001 . A$, SP-induced behaviors were inhibited by pretreatment with Con A. $B$, The response to NMDA was not altered by pretreatment with Con A. $C$ and $D$, The development of sensitization to KA and to Quis was completely blocked by pretreatment with Con A. The response to a single injection of Quis was also inhibited, suggesting either inhibition of other meditators in the CBS behavior or a very rapid development of sensitization, perhaps within the first $2 \mathrm{~min}$.

with NMDA, SP, KA, or Quis and the magnitude of the response to EAA or tachykinin was compared to vehicle-injected control mice as shown in Table 1. These results indicate that pretreatment with a series of three injections of either NMDA or SP cross-desensitized each other to the same degree. Pretreatment with NMDA, however, failed to alter the intensity of CBS behaviors in response to either $\mathrm{KA}$ or Quis, suggesting that the mechanisms involved in NMDA-induced desensitization involve different neuronal paths than those mediating the CBS responses produced by either KA or Quis. Pretreatment with three injections of SP, however, potentiated the response to a subsequent injection of KA but had no effect on the response to Quis.
Cross-sensitization. To determine whether pretreatment with either KA or Quis produced cross-sensitization, mice were pretreated with three injections of either of these compounds and then challenged with a fourth injection of NMDA, SP, KA, or Quis, as shown in Table 1. The magnitude of the final CBS response to this fourth injection was then compared to the effect of that compound after vehicle injections only. Following this protocol, pretreatment with Quis was found to potentiate the KA-induced CBS behavior and pretreatment with KA enhanced the intensity of Quis-induced behaviors, indicating complete cross-sensitization between the two EAAs. While pretreatment with Quis enhanced the effect of KA, it had no effect on the ability of either NMDA or SP to elicit CBS behaviors. Pretreat- 

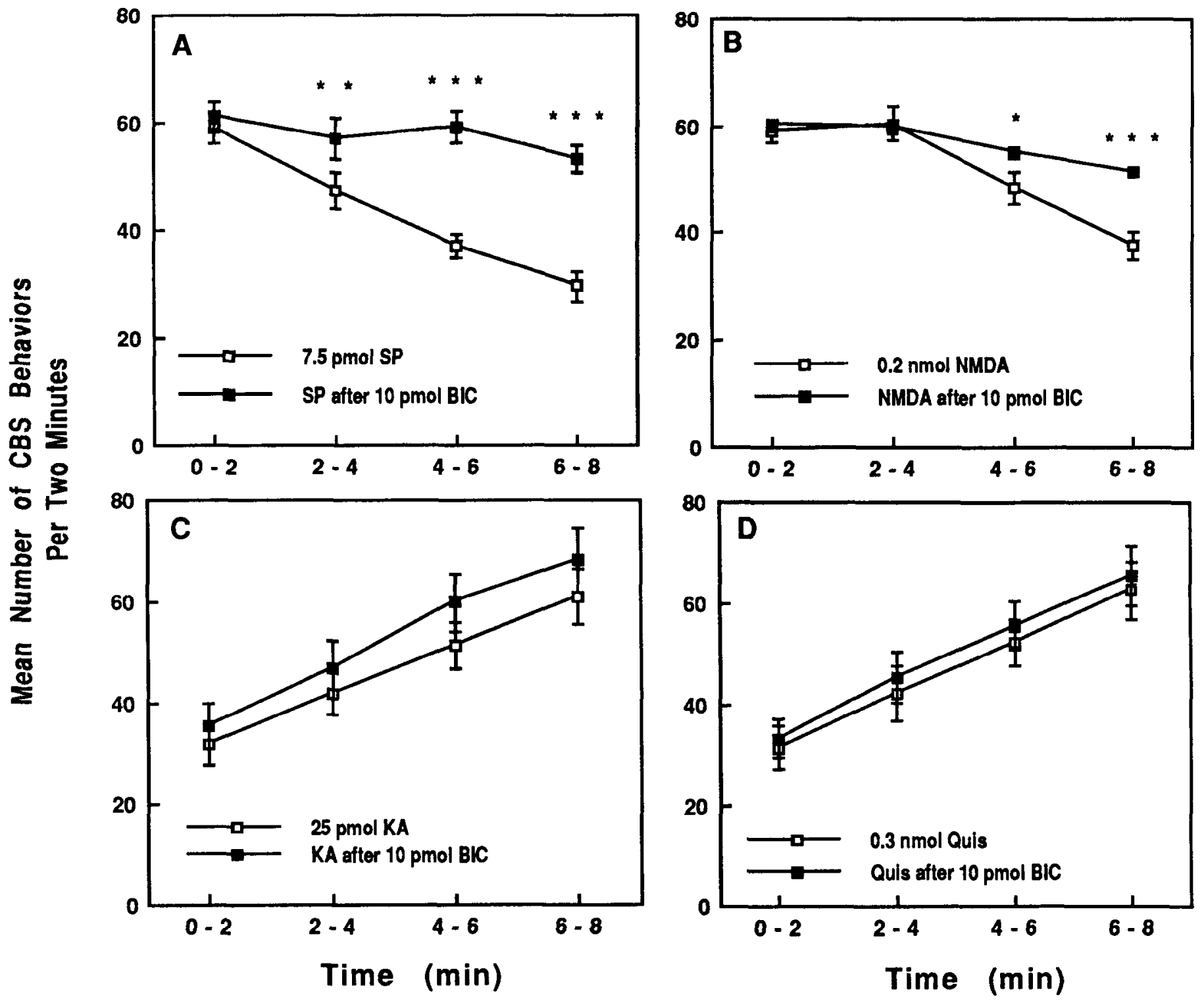

Figure 6. Inhibition of desensitization to the behavioral effects of SP and NMDA by bicuculline (BIC), a GABA antagonist. Groups of five mice were pretreated with saline or $10 \mathrm{pmol}$ of bicuculline $1 \mathrm{~min}$ prior to injection of SP or EAAs. Each point represents the mean number ( \pm SE) of CBS behaviors. Asterisks represent significant differences determined by Student's $t$ test between bicuculline and control groups at the time points indicated: ${ }^{*}, p<0.05 ;^{* *}, p<0.01$; and ${ }^{* * *}, p<0.001$. A, Blockade of SP-induced desensitization by bicuculline. $B$, Inhibition of desensitization to NMDA by bicuculline. $C$, Responses to repeated injections of KA were not affected by bicuculline. $D$, Responses to repeated injections of Quis were also unchanged by bicuculline.

Table 1. Occurrence of cross-"sensitization" ar cross-“desensitization"

Percentage of control ${ }^{b}$ behavioral response after injection of:

\begin{tabular}{lllll} 
Pretreatment $^{a}$ & NMDA & SP & KA & Quis \\
\hline NMDA & - & $51.0 \pm 6.5^{* * *}$ & $120.5 \pm 13.5$ & $90.0 \pm 10.7$ \\
SP & $53.2 \pm 5.9^{* * *}$ & - & $194.2 \pm 13.5^{* * *}$ & $100.0 \pm 5.4$ \\
KA & $53.2 \pm 4.2^{* * *}$ & $90.5 \pm 2.9^{* *}$ & - & $171.6 \pm 7.9^{* * *}$ \\
Quis & $112.9 \pm 6.8$ & $105.2 \pm 2.36$ & $193.2 \pm 12.6^{* * *}$ & -
\end{tabular}

$n=$ at least 5 mice per group.

${ }^{a}$ Compounds listed vertically were administered as a pretreatment intrathecally three times at $2 \mathrm{~min}$ intervals. The third of these injections was 2 min prior to injection of the compound listed horizontally.

' Control values were obtained by pretreatment with vehicle.

*, Values that are significantly different than those after vehicle as determined using Student's $t$ test for unpaired samples.

${ }^{* *}, p<0.01 ;{ }^{* * *}, p<0.001$. 

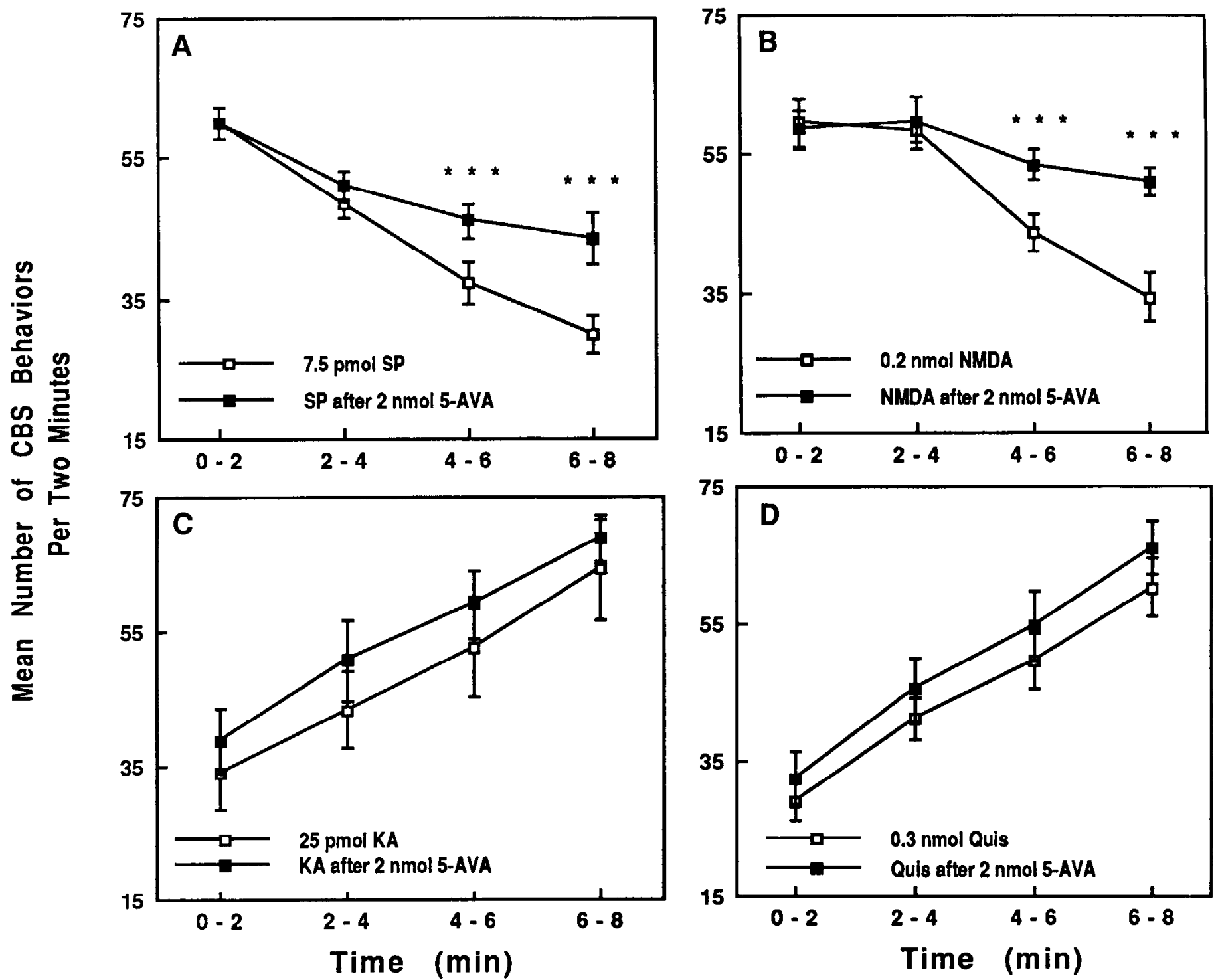

Figure 7. Protection against desensitization by 5-AVA, a $\mathrm{G} \wedge \mathrm{BA} \mathrm{B}_{\mathrm{B}}$ antagonist. Groups of five mice were pretreated intrathecally with either saline or $2 \mathrm{nmol}$ of 5-AVA $5 \mathrm{~min}$ prior to repeated injection of excitatory compounds. Each point represents the average number ( \pm SE) of CBS behaviors produced during a 2 min interval after injection of each compound. Asterisks represent significant differences between the 5-AVA and control groups: ${ }^{* * *}, p<0.001$. $A$, Desensitization to SP was inhibited by 5 -AVA during the third and fourth injections. $B$, Desensitization to NMDA was inhibited by 5-AVA. $C$, Responses to KA injection were not affected by 5-AVA. D, Quis-induced CBS behaviors also were not altered by 5-AVA.

ment with KA, however, not only failed to potentiate the response to NMDA and SP but significantly inhibited the response produced by these two compounds. The inhibitory effect of pretreatment with KA on the response to NMDA was greater than that on the response to SP.

\section{Discussion}

Several lines of investigation support the involvement of SP and EAAs in the mediation of pain perception in the spinal cord. Substance P and SP binding sites (Hokfelt et al., 1975; Mudge et al., 1979; Helke et al., 1986) as well as EAAs and EA receptors (Duggan and Johnston, 1970; Greenmyre et al., 1984; Weinberg et al., 1987) have been localized in superficial laminae of the dorsal horn, an area thought to be important in nociception. Noxious stimulation causes release of SP (Takagi, 1984) as well as the release of Glu and Asp (Skilling et al., 1988), while intrathecal injection of either SP (Yashphal and Henry, 1983) or NMDA (Aanonsen and Wilcox, 1987) results in hyperalgesia. It has been postulated that primary and secondary hyperalgesia caused by exposure to noxious stimulation is mediated in part by changes in spinal cord or other higher-order neurons (Kenshalo et al., 1982; LaMotte, 1984) in addition to changes in the peripheral tissue. Release of EAAs from large-diameter primary afferent fibers has also been proposed to be important in the mediation of neuropathic pain disorders such as allodynia, causalgia, or neuralgias (Willer et al., 1978, 1983; Bennett and Xie, 1988; Campbell et al., 1988; Bennett et al., 1989).

Tonic changes in the sensitivity to SP and EAAs may play a role in primary or secondary hyperalgesia or in chronic pain. It is not known whether the intrathecal injection of these compounds, which produces CBS behavior in mice, is sufficient to elicit pain (Frenk et al., 1988); however, this model allows us to study changes in the activity of compounds thought to be involved in nociception. Based on our previous work showing 

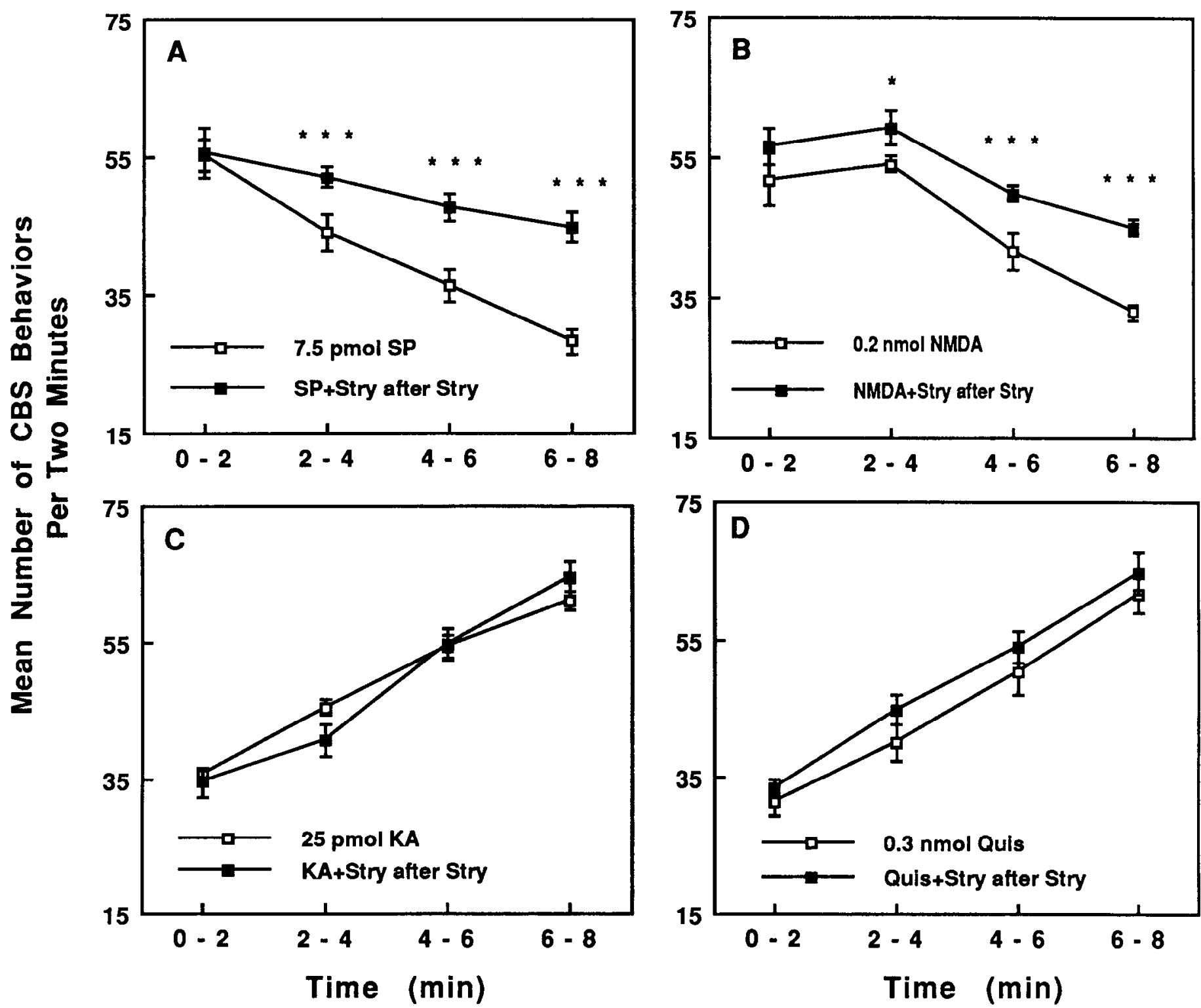

Figure 8. Inhibition of desensitization to the behavioral effects of SP and NMDA by strychnine. Groups of five mice were pretreated intrathecally with either saline or $0.3 \mathrm{nmol}$ of strychnine $(S t r y) 1 \mathrm{~min}$ prior to repeated injection of excitatory compounds. Mice receiving strychnine were also coadministered $75 \mathrm{pmol}$ of strychnine with each injection of excitatory compound. Each point represents the average number ( \pm SE) of CBS behaviors produced during a 2 min interval after injection of each compound. Asterisks represent significant differences between the strychnine and control groups: ${ }^{*}, p<0.05{ }^{* * *}, p<0.001$. $A$, Desensitization to SP was inhibited by strychnine. $B$, Desensitization to NMDA was inhibited by strychnine. $C$, Responses to KA were not affected by strychnine. $D$, Quis-induced CBS behaviors also were not altered by strychnine.

a desensitization to the behavioral effects of SP, we hypothesized that the behavioral activity produced by repeated injections of EAAs in the spinal cord may also differ from that elicited by their single injection. Electrophysiological studies describe the tendency of EAA-mediated events to desensitize (Trussell et al., 1988; Mayer et al., 1989) or sensitizc (Kaucr ct al., 1988). Our data reflect a change in the response to repeated injections of EAAs, resulting in a rapidly developing sensitization to the CBS behavioral effects of KA or Quis and desensitization to repeated injections of SP and NMDA. Prolongation of the dosing interval to allow complete dissipation of each behavioral effect did not interfere with the enhancement of CBS, suggesting that the enhanced response is not simply due to an accumulation of drug.

The development of sensitization to KA and Quis, as opposed to desensitization to NMDA and SP, is significant as it clearly indicates that (1) not all EAA receptors elicit the same tonic activity, in spite of similar acute behavioral effects, and (2) there are unique modulatory systems for the tonic activities of these compounds in vivo. Not only was sensitization to KA and Quis distinct from desensitization to SP and NMDA, but, as illustrated in Table 1, the tonic effect of each excitatory compound on the response to challenge with either SP, NMDA, KA, or Quis resulted in a unique profile.

The phenomenon of behavioral sensitization to KA has several parallels to "windup" of class 2 neurons of the rat dorsal horn in response to repeated electrical stimulation of their receptive fields (Davies and Lodge, 1987). Windup was only evoked by stimulus currents that were sufficient to evoke a C-fiber vol- 

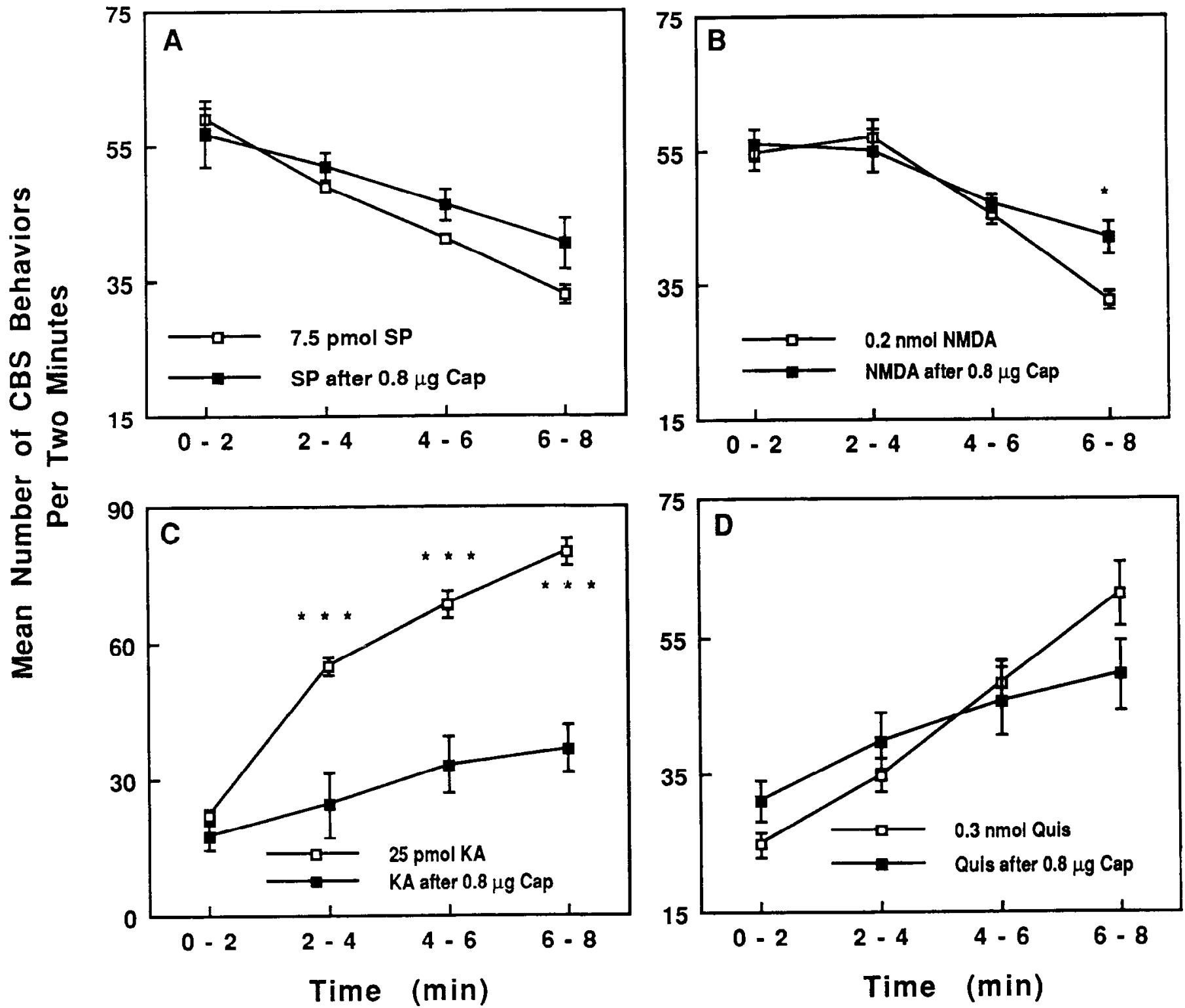

Figure 9. Attenuation of sensitization to the behavioral effects of KA by pretreatment with capsaicin (Cap). Mice were pretreated with $0.8 \mu \mathrm{g}$ of capsaicin or the vehicle, $50 \%$ saline and $50 \%$ DMSO, $24 \mathrm{hr}$ prior to injection of each excitatory compound. Each point represents the average number $( \pm \mathrm{SE}$ ) of CBS behaviors produced during a 2-min interval after injection of each compound. Asterisks represent significant differences between the capsaicin and control group: ${ }^{*}, p<0.05 ;{ }^{* * *}, p<0.001$. $A$, Desensitization to SP was inhibited slightly by capsaicin. $B$, Desensitization to NMDA was inhibited only slightly by capsaicin. $C$, Responses to KA wcrc grcatly attenuated by capsaicin pretreatment. $D$, Quis-induced CBS behaviors were not altered by capsaicin.

ley. Stimulation with currents that evoked only A-fiber responses did not induce windup. The possibility that behavioral sensitization to $\mathrm{KA}$ is similarly mediated by the release of SP is consistent with capsaicin's ability to inhibit sensitization to KA and SP's ability to potentiate the behavioral response to $\mathrm{KA}$. Our preliminary results show that KA is capable of evoking the releasc of SP in the rat spinal cord (Murray et al., 1990). In light of the widely held belief that small-diameter C-fibers release SP while larger-diameter fibers would more likely release EAAs and not SP, it is reasonable to postulate that windup involves release of SP, which potentiates the response to endogenously released EAAs in a manner similar to that seen during behavioral sensitization to KA.

It has been proposed that interneuronal transmission is mediated by Asp (Stone and Burton, 1988) interacting with NMDA receptors (Watkins and Evans, 1981). To discern whether sensitization or desensitization is mediated by NMDA activity, we determined the effect of APV, an NMDA antagonist, on behavioral responses to each excitatory compound. We chose a dose of APV that significantly inhibited but did not block the response to NMDA to ensure that any effect of APV observed was not simply due to paralysis. The insensitivity of KA or Quis to APV indicates that the NMDA receptor is not involved in the generation of their acute behavioral effects or in the development of behavioral sensitization. We (Smullin et al., 1990) and others (Aanonsen and Wilcox, 1986) have not previously observed an inhibition of the SP when coadministered with APV. After testing several doses and pretreatment intervals, we found that coadministration of SP with $1 \mathrm{nmol}$ of APV docs not inhibit the response to a single injection of SP, but pretreat- 
ment with the same dose of APV inhibits the response to SP without altering the rate of development of desensitization, perhaps reflecting the time required for diffusion of the drug to its site of action. These data suggest a role for NMDA receptors in the response to SP and is consistent with our previous work showing that SP evokes the release of Glu and Asp in the spinal cord of the conscious, freely moving rat (Smullin et al., 1990).

The complete inhibition of KA- and Quis-induced sensitization by Con A suggests a possible link between sensitization to the behavioral effects of KA and Quis in vivo and desensitization to Quis seen electrophysiologically (Mayer and Vyklicky, 1989). Con A appears to act with some degree of selectivity as NMDA-induced desensitization is not altered by Con $A$ in either electrophysiologic or behavioral paradigms. While the lectin Con $A$ interacts with many glycosylated membrane proteins, it is of interest that Con A inhibited Quis receptor desensitization electrophysiologically but completely blocked the development of sensitization to the behavioral effects of both Quis and KA.

Baclofen, a $\mathrm{GABA}_{\mathrm{B}}$ agonist, is capable of inhibiting CBS activity caused by EAAs in the mouse spinal cord (Aanonsen and Wilcox, 1989), while intrathecal injection of muscimol, a GA$\mathrm{BA}_{\mathrm{A}}$ agonist, inhibits SP-induced CBS behaviors (Hwang and Wilcox, 1989). Behavioral descnsitization to NMDA and SP appears to be mediated, at least in part, by GABA. Our data, showing protection against the development of desensitization by either bicuculline, a $\mathrm{GABA}_{\mathrm{A}}$ antagonist, or 5-AVA, a $\mathrm{GABA}_{\mathrm{B}}$ antagonist, suggest that activation of GABAergic neurons does play a role in decreasing the behavioral response to SP and

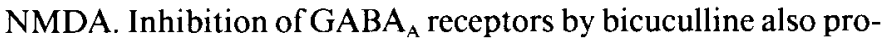
duces an enhanced response to non-noxious tactile stimulation (Yaksh, 1989), suggesting a possible link between allodynia and an inability to desensitize to NMDA.

Electrophysiologically, NMDA receptors desensitize more slowly in the presence of a high concentration of glycine (Mayer et al., 1989), which may contribute to the slow desensitization in the micromolar concentrations of glycine in the extracellular fluid (Skilling et al., 1988) compared to the nanomolar concentrations of glycine often used electrophysiologically (Mayer et al., 1989). The protection by strychninc against bchavioral desensitization to SP and NMDA in the present investigation further supports an involvement of glycine in this phenomenon. We have previously shown a strychnine-insensitive, glycineinduced enhancement of NMDA activity using this behavioral model (Larson and Beitz, 1988). Inhibition of desensitization by strychnine could result from either a decrease in glycine's strychnine-sensitive inhibitory actions or an unmasking of glycine's ability to facilitate NMDA activity via the strychnineinsensitive glycine site. The dose of strychnine used in the present study was based on a dose that produced no CBS behavior when injected alone, had no effect on the intensity of behaviors elicited by a single injection of either SP or NMDA, yet was sufficient to convert the inhibitory effect of $50 \mu \mathrm{g}$ of glycine on NMDA-induced behaviors to a potentiative effect, suggesting a complete inhibition of the inhibitory glycine receptors and an unmasking of the strychnine-insensitive glycine sites. Potentiation in CBS behaviors during desensitization would therefore likely result from an enhanced release of glycine.

There are a number of observations that support the hypothesis that separate KA and Quis receptors exist in our system (Hornfeldt and Larson, 1989) as well as others (Foster and Fagg, 1984). The present study is consistent with the theory that KA and Quis activate two separate receptors to elicit CBS behaviors. KA and Quis each exhibit different times of recovery from behavioral sensitization and interactions with SP. Pretreatment with KA, but not Quis, decreased responses to NMDA and SP, and pretreatment with SP in turn enhanced the behavioral response to KA but not Quis. While behavioral sensitization to KA appears to be due to a capsaicin-sensitive effect, the mechanism underlying behavioral sensitization to Quis is not clear.

Desensitization to the behavioral effects of SP is reversible by a relatively high dose of naloxone (Larson, 1988), suggesting that endogenous opioid activity is, at least in part, responsible for the development of desensitization to SP. The phenomenon of desensitization to SP parallels its role as a nociceptive transmitter as SP has been shown to produce a naloxone-reversible analgesia. SP is metabolized in the spinal cord to $\mathrm{N}$-terminal peptide fragments (Igwe et al., 1990a) that are capable of inhibiting the CBS response to SP (Sakurada et al., 1988; Igwe et al., 1990a) perhaps by a direct interaction with a $\beta$-FNA-insensitive subtype of $\mu$-opioid receptor (Krumins et al., 1989, 1990) or via novel SP N-terminal receptors (Igwe et al., 1990b,c).

Changes in the tonic activity of EAAs may be important in a variety of physiologic or pathologic situations such as seizures, excitotoxicity, ischemia, and anoxia. In studies using embryonic tissue cultures, $\mathrm{K} \Lambda$-induced toxicity is proposed to result from a lack of desensitization to KA receptors (Vyklicky et al., 1986). One might speculate that KA toxicity may be mediated by similar events that lead to the development of behavioral sensitization to KA or Quis.

In summary, the intensity of CBS behaviors produced by NMDA, KA, Quis, and SP in the mouse spinal cord changes after tonic exposure. Behavioral responses to SP and NMDA decrease while responses to KA and Quis dramatically increase. While NMDA receptor activation appears to be necessary for SP-induced behaviors, reflecting the release of endogenous EAAs, enhanced NMDA activity does not account for sensitization to KA or Quis. The inhibition of desensitization to SP and NMDA by GABA and glycine antagonists supports the hypothesis that behavioral desensitization results from enhanced activity of inhibitory GABA, and possibly glycine, interneurons. Documentation that sensitization to $\mathrm{KA}$ and Quis develops in vivo and that SP selectively potentiates subsequent $\mathrm{KA}$ activity is important as EAAs have been proposed to play a role in chronic pain, neuromas, excitotoxicity, and seizures.

\section{References}

Aanonsen LM, Wilcox GL (1986) Phencyclidine selectively blocks a spinal action of $N$-methyl-D-aspartate in mice. Neurosci Lett 67:191197.

Aanonsen LM, Wilcox GL (1987) Nociceptive action of excitatory amino acids in the mouse: effects of spinally administered opioids, phencyclidine and sigma agonists. J Pharmacol Exp Ther 243:9-19.

Aanonsen LM, Wilcox GL (1989) Muscimol, $\gamma$-aminobutyric acid receptors and excitatory amino acids in the mouse spinal cord. $\mathbf{J}$ Pharmacol Exp Ther 248:1034-1038.

Bennett GJ, Xie Y-K (1988) A peripheral mononeuropathy in rat that produces disorders of pain sensitization like those seen in man. Pain 33:87-107.

Bennett GJ, Kajander KC, Sahara Y, Iadarola MJ, Sugimoto T (1989) Neurochemical and anatomical changes in the dorsal horn of rats with an experimental painful peripheral neuropathy. In: NATO ASI Series, Ser A, Life Sciences, Vol 176, Processing of sensory information in the superficial dorsal horn of the spinal cord (Cervero F, Bennett GJ, Headle PM, eds), pp 463-471. New York: Plenum.

Besson J, Chaouch A (1987) Peripheral and spinal mechanism of nociception. Physiol Rev 67:67-185.

Cahusac PMB, Evans RH, Hill RG, Rodriquez RE, Smith DAS (1984) 
The behavioral effects of an $N$-methylaspartate receptor antagonist following application to the lumbar spinal cord of conscious rats. Neuropharmacology 23:719-724.

Campbell JN, Raja SN, Meyer RA, MacKimon SE (1988) Myelinated afferents signal the hyperalgesia associated with nerve injury. Pain 32:89-94.

Davies SN, Lodge D (1987) Evidence for involvement of $N$-methylaspartate receptors in 'wind-up' of class 2 neurons in the dorsal horn of the rat. Brain Res 424:402-406.

De Biasi S, Rustioni A (1988) Glutamate and substance P coexist in primary afferent terminals in superficial laminae of spinal cord. Proc Natl Acad Sci USA 85:7820-7824.

Duggan AW, Johnston GAR (1970) Glutamate and related amino acids in cat spinal roots, dorsal root ganglia and peripheral nerves. J Neurochem 17:1205-1208.

Evans RH, Francies AA, Watkins JC (1978) $\mathrm{Mg}^{2+}$-like selective antagonism of excitatory amino acid-induced responses $\alpha, \epsilon$-diaminopimelic acid, D- $\alpha$-aminoadipate and HA-966 in isolated spinal cord of frog and immature rat. Brain Res 148:536-542.

Evans RH, Francies AA, Hunt K, Oakes DJ, Watkins JC (1979) Antagonism of excitatory amino acid-induced responses and of synaptic excitation in the isolated spinal cord of the frog. $\mathrm{Br} \mathrm{J}$ Pharmacol 67: 591-603.

Foster AC, Fagg GE (1984) Acidic amino acid binding sites in mammalian neuronal membranes: their characteristics and relationship to synaptic receptors. Brain Res Rev 7:103-164.

Frenk H, Bossut D, Urca G, Mayer DJ (1988) Is substance P a primary afferent neurotransmitter for nociceptive input? I. Analysis of painrelated behaviors resulting from intrathecal administration of substance $\mathrm{P}$ and 6 excitatory compounds. Brain Res 455:223-231.

Greenmyre JT, Young AB, Penney JB (1984) Quantitative autoradiographic distribution of $\mathrm{L}-\left[{ }^{3} \mathrm{H}\right]$ glutamate-binding sites in rat central nervous system. J Neurosci 4:2133-2144.

Hall ME, Stewart JM (1986) Substance P and antinociception. Peptides 4:31-35.

Helke CJ, Charlton CG, Wiley RG (1986) Studies on the cellular localization of spinal cord substance $P$ receptors. Neuroscience 19 : $523-533$

Hokfelt T, Kellerth J-O, Nilsson G, Pernow B (1975) Substance P: localization in the central nervous system and in some primary sensory neurons. Science 190:889-890.

Hornfeldt CS, Larson AA (1989) Selective inhibition of excitatory amino acids by divalent cations. A novel means for distinguishing $N$-methyl-D-aspartate acid-, kainate- and quisqualate-mediated actions in the mouse spinal cord. J Pharmacol Exp Ther 251:10641068 .

Hwang AS, Wilcox GL (1989) Baclofen, $\gamma$-aminobutyric acid $_{B}$ receptors and substance $P$ in the mouse spinal cord. J Pharmacol Exp Ther 248:1026-1033.

Hylden JLK, Wilcox GL (1980) Intrathecal morphine in mice: a new technique. Fur J Pharmacol 67:313-316.

Hylden JLK, Wilcox GL (1981) Intrathecal substance P elicits a caudally-directed biting and scratching behavior in mice. Brain Res 217 $212-215$

Igwe JO, Sun X, Larson AA (1990a) Role of substance P amino terminal metabolites in substance P-induced desensitization in mice Neuroscience 36:535-542.

Igwe JO, Kim DC, Seybold VS, Larson AA (1990b) Effects of ions and nucleotides on the binding of substance $P$ aminoterminal heptapeptide in CNS membranes. Soc Neurosci Abstr 220:515.

Igwe JO, Kim DC, Seybold VS, Larson AA (1990c) Specific binding of substance $P$ aminoterminal heptapeptide [SP(1-7)] to mouse brain and spinal cord membranes. J Neurosci 10:3653-3663.

Kauer JA, Malenka RC, Nicoll RA (1988) NMDA application potentiates synaptic transmission in the hippocampus. Nature 334:250252.

Kenshalo DR Jr, Leonard RB, Chung JM, Willis WD (1982) Facilitation of the responses of primate spinolthalamic tract cells to cold and to tactile stimuli by noxious heating of the skin. Pain 12:141152.

Krumins SA, Kim DC, Seybold VS, Larson AA (1989) Modulation of $\left[{ }^{3} \mathrm{H}\right] \mathrm{DAGO}$ binding by substance $\mathrm{P}$ (SP) and SP fragments in the mouse brain and spinal cord via $\mathrm{MU}_{1}$ interactions. Neuropeptides 13:225-233.

Krumins SA, Kim DC, Larson AA (1990) Substance P modulation of DAMGO binding in the brain of CXBK and Swiss-Webster mice. Peptides 11:281-285.

LaMotte RH (1984) Can the sensitization of nociceptors account for hyperalgesia after skin injury? Hum Neurobiol 3:47-52.

Larson AA (1988) Desensitization to intrathecal substance $P$ in mice: possible involvement of opioids. Pain 32:367-374.

Larson AA (1989) Intrathecal GABA, glycine, taurine or beta-alanine elicits dyskinetic movements in mice. Pharmacol Biochem Behav 32: 505-509.

Larson AA, Beitz AJ (1988) Glycine potentiates strychnine-induced convulsions: role of NMDA receptors. J Neurosci 8:3822-3826.

Laufer R, Gilon C., Chorev M, Selinger Z (1988) Desensitization with a selective agonist discriminates between multiple tachykinin receptors. J Pharmacol Exp Ther 245:639-643.

Lembeck F (1953) Zur Frage der zentralen Ubertragung afferenter Impulse. III. Mitteilung. Das Vorkommen und die Bedentung der Substanz $\mathrm{P}$ in den dorsalen Wurzeln des Ruckenmarks. Naunyn Schmiedebergs Arch Exp Pathol Pharmacol 219:197-213.

Mayer ML, Vyklicky L Jr (1989) Concanavalin A selectively reduces desensitization of mammalian neuronal quisqualate receptors. Proc Natl Acad Sci USA 86:1411-1415.

Mayer ML, Westbrook GL (1985) The action of $N$-methyl-D-aspartatic acid on mouse spinal neurones in culture. J Physiol (Lond) 361: 65-90.

Mayer ML, Vyklicky L Jr, Clements J (1989) Regulation of NMDA receptor desensitization in mouse hippocampal neurons by glycine. Nature 338:425-427.

McLennan H, Lodge D (1979) The antagonism of amino acid-induced excitation of spinal neurones in the cat. Brain Res 169:83-90.

Moochhala SM, Sawynok J (1984) Hyperalgesia produced by intrathecal substance $P$ and related peptides: desensitization and cross desensitization. Br J Pharmacol 82:381-388.

Mudge AW, Leeman SE, Fischbach GD (1979) Enkephalin inhibits release of substance $P$ from sensory neurons in culture and decreases action potential duration. Proc Natl Acad Sci USA 76:526-530.

Murray CW, Skilling SR, Smullin DH, Larson AA (1990) Release of substance $\mathrm{P}$ in the dorsal lumbar spinal cord of the conscious, freely moving rats: stimulation by kainic acid, capsaicin and substance $\mathbf{P}(1$ 7) Soc Neurosci Abstr 73:161.

O'Brien RJ, Fischbach GD (1986) Characterization of excitatory amino acid receptors expressed by embryonic chick motoneurons in vitro. J Neurosci 6:3275-3283.

Picrcey MF, Dobry PJK, Schocder LA, Einspahr FJ (1981) Bchavioral evidence that substance $P$ may be a spinal cord sensory neurotransmitter. Brain Res 210:407-412.

Sakurada T, Kuwahara H, Takahashi K, Sakurada S, Kisara K, Terenius L (1988) Substance $P(1-7)$ antagonizes substance $P$-induced aversive behavior in mice. Neurosci Lett 95:281-285.

Salt TE, Hill RG (1983) Neurotransmitter candidates of somatosensory primary afferent fibers. Neuroscience 10:1083-1103.

Schneider SP, Perl ER (1988) Comparison of primary afferent and glutamate excitation of neurons in the mammalian spinal dorsal horn. J Neurosci 8:2062-2073.

Skilling SR, Smullin DH, Larson AA (1988) Extracellular amino acid concentration in the dorsal spinal cord of freely moving rats following vertridine and nociceptive stimulation. J Neurochem 51:127-132.

Smullin DII, Skilling SR, Larson AA (1990) Interaction between substance $P$, calcitonin gene related peptide, taurine and excitatory amino acids in the spinal cord. Pain 42:93-101.

Stone TW, Burton NR (1988) NMDA receptors and ligands in the vertebrate CNS. Prog Neurobiol 30:333-368.

Takagi H (1984) Experimental pain and neuropeptides. Clin Ther 7: $35-47$.

Takeuchi A, Takeuchi N (1964) The effect on crayfish muscle of iontophoretically applied glutamate. J Physiol (Lond) 170:296-317.

Tang C-M, Dichter M, Morad M (1989) Quisqualate activates a rapidly inactivating high conductance ionic channel in hippocampal neurons. Science 243:1474-1477.

Trussell LO, Thio LL, Zorumski CF, Fischbach GD (1988) Rapid desensitization of glutamate receptors in vertebrate central neurons. Proc Natl Acad Sci USA 85:2834-2838.

Vyklicky L, Vyklicky L Jr, Vyskocil F, Vlachova V, Ulec E, Michl J (1986) Evidence that excitatory amino acids not only activate the receptor channel complex but also lead to use-dependent block. Brain Res 363:148-151. 
Watkins JC, Evans RH (1981) Excitatory amino acid transmitters. Annu Rev Pharmacol Toxicol 21:165-204.

Weinberg RJ, Conti F, Van Eyck SL, Petrusz P, Rustioni A (1987) Excitatory amino acid transmission. In: Neurology and neurobiology (Hicks TP, Lodge D, McLennen H, eds), pp 173-176. New York: Liss.

Wilcox GL (1988) Pharmacological studies of grooming and scratching behavior elicited by spinal substance $P$ and excitatory amino acids. Ann NY Acad Sci 525:228-236.

Willcr J-C, Bourcau F, Able-Fessard D (1978) Role of large diameter cutaneous afferents in transmission of nociceptive messages: electrophysiological study in man. Brain Res 152:358-364.

Willer J-C, Boureau F, Able-Fessard D (1983) Human nociceptive reaction: effects of spatial summation of afferent input from relatively large diameter fibers. Brain Res 201:465-470.

Yaksh TL (1989) Behavioral and autonomic correlates of the tactile evoked allodynia produced by spinal glycine inhibition: effects of modulatory receptor systems and excitatory amino acid antagonists. Pain 37:111-123.

Yashpal K, Henry JI. (1983) Fndorphins mediate overshoot of suhstance $\mathbf{P}$-induced facilitation of a spinal nociceptive reflex. Can $\mathbf{J}$ Physiol Pharmacol 61:303-307.

Zorumski CF, Yang J, Fischbach GD (1989) Calcium-dependent, slow desensitization distinguishes different types of glutamate receptor. Cell Mol Neurobiol 9:95-104. 